Check for updates

Cite this: RSC Adv., 2018, 8, 25313

\title{
A novel self-healing power cable insulating material based on host-guest interactions $\uparrow$
}

\author{
Lei Peng, (D)*ab Manjun Zhang, ${ }^{a}$ Musong Lin ${ }^{a}$ and Qiang Fu ${ }^{a}$ \\ The insulating materials used in power cables are susceptible to damage and cracks during installation and \\ operation. To solve this problem, we have prepared a self-healing material PVP/p(HEMA-co-BA), which is \\ synthesized by radical polymerization using HEMA, BA, PVP and a host-guest assembly. The host-guest \\ assembly is constructed through interactions between host and guest molecules (CD- $\mathrm{Al}_{2} \mathrm{O}_{3} \mathrm{NPs}$ act as \\ the host, and HEMA-Ad acts as the guest). The characterization results of the materials show that there \\ are two kinds of supramolecular interactions, namely, the host-guest interaction and the hydrogen \\ bonding. The material possesses good thermal stability (heat-resisting temperature can reach $200{ }^{\circ} \mathrm{C}$ ) \\ and good electrical performance. The storage modulus of the material can be increased up to $432 \mathrm{MPa}$ \\ using a cross-linking agent at $20^{\circ} \mathrm{C}$. Furthermore, the material exhibits self-healing property, and it can \\ self-heal several times; its self-healing efficiency is relative to the dosage of the cross-linking agent.
}

Received 7th June 2018

Accepted 2nd July 2018

DOI: $10.1039 / \mathrm{c} 8 \mathrm{ra04882g}$

rsc.li/rsc-advances

\section{Introduction}

Insulating material of a power cable is the outermost protective layer of the cable core, and it is exposed to the external environment directly. During the process of installation and operation, damages caused by aging and external forces affect the service life and even cause leakage and blackout accidents, thereby incurring tremendous economic losses and compromising safety. ${ }^{\mathbf{1 , 2}}$ For example, in 2011, across China, 15 of 48 (31\%) cable accidents resulted from external damages. ${ }^{3}$ At present, methods available for repairing the damage to the cable insulating layer mainly include injected liquid method, heat-sealing method, and thermal contractible tube method; however, these three types of repair methods have disadvantages such as complex steps and poor repairing effect, and they also require the fault location technique to find out the fault points, due to which they are difficult to operate. ${ }^{4}$ Therefore, there is a need to develop new techniques to repair damaged cable insulation.

Self-healing materials (SHMs) are a type of smart materials that can automatically identify damages or structural defects (perceive) and repair them (respond) partially or completely. ${ }^{5}$ Considering this feature of automatic identification and repair, we have attempted to introduce such self-healing supramolecular monomers into the insulating material of power cables for damage repair.

\footnotetext{
${ }^{a}$ Electric Science and Research Institute of Guangdong Power Grid Co. Ltd, China. E-mail:penglei1025@whu.edu.cn

${ }^{b}$ School of Electrical Engineering, Chongqing University, China

$\dagger$ Electronic supplementary information (ESI) available. See DOI: 10.1039/c8ra04882g
}

At present, one type of self-healing material (the filling type) exhibits self-healing property due to the repair agent carriers such as hollow fibers, ${ }^{6,7}$ microcapsules, ${ }^{8-10}$ or microvasculatures, ${ }^{\mathbf{1 1 , 1 2}}$ which are dispersed in the polymer matrix. When the material is damaged, the carriers break down, and the repair agents release and diffuse to the crack location. The repair agents can initiate cross-linking reactions to achieve the purpose of repairing. Although such materials can self-repair, it is difficult to achieve repeated repairs due to the limited capacity of the repair agents. However, another kind of self-healing materials repair the defects through the intermolecular interactions of their components. These have the advantages of repeated repair times, which are not restricted by the capacity of the repair agents. The mechanism of such kind of self-healing materials is based on dynamic covalent bonds. Under the stimulation of external factors such as thermal energy, ${ }^{13}$ light $^{14}$ and $\mathrm{pH},{ }^{15}$ reversible cleavage and generation of intermolecular covalent bonds occur. In the process of covalent bond regeneration, the cracks can be repaired. However, in the actual environment in which the power cable insulation sheath exists, the above-mentioned external stimulating factors are not present, which hinders the self-healing efficiency of these materials.

Based on the research of this kind of covalent bond-based self-healing model, scientists have widened the research field to non-covalent bond models. The self-healing property is gained mainly due to the presence of non-covalent bonds such as hydrogen bonds, ${ }^{16} \pi-\pi$ bonds, ${ }^{17,18}$ and metal coordination bonds ${ }^{19}$ as well as topology structure. ${ }^{20}$ The most important advantage of such materials is that they do not require external stimulatory factors to activate the self-repair property; among these, a particular kind of supramolecular material based on a host-guest interaction model is of great interest. 
Currently, basic research on the host-guest interaction model has been carried out, and researchers have also developed materials with excellent repairing effects. For example, the group led by Professor Huang at Zhejiang University has developed two kinds of supramolecular gels based on host-guest reactions; these gels exhibit excellent self-healing performance, and they can rapidly self-heal even under $10000 \%$ strain. $^{21}$ Professor Mynar's group from Tokyo University has prepared a gel that can self-heal completely, and it is synthesized using clay and telechelic dendritic macromolecules with multiple adhesive termini. ${ }^{22}$ The group of Zhang in Sichuan University has developed an elastomer that can restore $90 \%$ of its mechanical strength rapidly. ${ }^{23}$ However, the mechanical properties of these self-healing materials have been proven to be unsatisfactory (some materials are even "jelly-like"). ${ }^{24}$ The Young's modulus of self-healing materials based on non-covalent bonds is generally in the range of 1-10 $\mathrm{MPa} .^{16,25}$ Therefore, to meet the requirements for use as a cable material, enhancing the mechanical strength of the self-healing material is of great significance.

Therefore, in this paper, we proposed a new PVP/p(HEMA-coBA) self-healing material with suitable mechanical strength. The material adopted a host-guest interaction topology model, and the guests were grafted by special reinforcements. The host-guest assembly was then prepared by free-radical copolymerization with HEMA, BA, and PVP to obtain the self-healing material having suitable mechanical strength.

\section{Principle}

In this study, the host-guest inclusion model is used for the synthesis of a self-healing material with $\beta$-cyclodextrin as the host and adamantane as the guest. The $\beta$-cyclodextrin molecule has a lipophilic cavity inside, whereas adamantane shows excellent lipophilicity. Moreover, the size of the cavity in $\beta$-cyclodextrin is $0.7-0.8 \mathrm{~nm}$, and the diameter of adamantane molecule is about $0.7 \mathrm{~nm} .{ }^{26}$ Thus, the host and guest molecules match perfectly in size, which means that adamantane can fit in the cavity of cyclodextrin firmly. When the material is damaged, based on the lipophilic cavity of $\beta$-cyclodextrin and the oleophilic structure of the adamantyl group, the adamantane group is stuck inside the cavity of the cyclodextrin molecule by the same polar attractive force, resulting in a stable supramolecular network. Thus, the damage is healed. The process of preparation of the PVP/ $\mathrm{p}$ (HEMA-co-BA) self-healing material is shown in Fig. 1.

\section{Materials and methods}

\subsection{Materials}

2-Hydroxyethyl-methacrylate (HEMA), $\beta$-cyclodextrin ( $\beta$-CD), butyl acrylate (BA), azobisisobutyronitrile (AIBN, 99\%, recrystallization), polyvinylpyrrolidone (PVP-K30, $\mathrm{Mn}=40000), \mathrm{Al}_{2} \mathrm{O}_{3}$ nanoparticles $\left(\mathrm{NH}_{2}-\mathrm{Al}_{2} \mathrm{O}_{3} \mathrm{NPs}, 30 \mathrm{~nm}, \alpha\right.$-phase), ethylene glycol dimethacrylate (EGDMA), (3-aminopropyl) triethoxysilane (APTES), and adamantanecarboxylic acid (Ad-COOH) were obtained from Aladdin (Shanghai) Reagent Co., Ltd. Hydrochloric acid, dichloromethane $\left(\mathrm{CH}_{2} \mathrm{Cl}_{2}\right)$, dimethyl sulfoxide (DMSO), $p$-toluenesulfonyl chloride (TOS-Cl), thionyl chloride $\left(\mathrm{SOCl}_{2}\right)$, and concentrated sulfuric acid

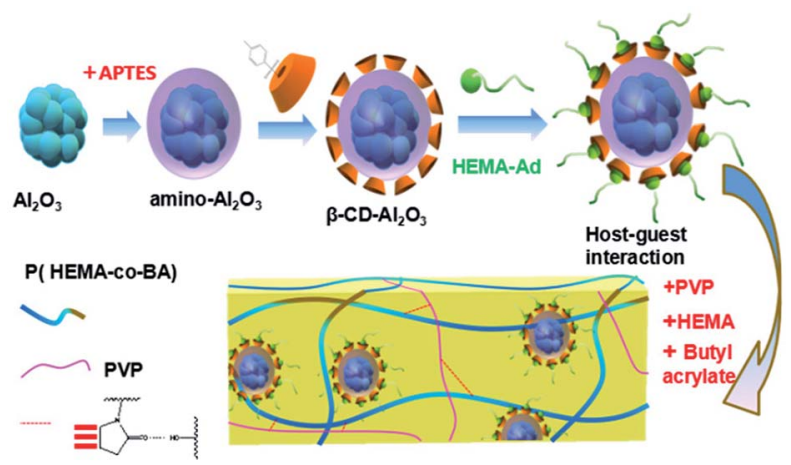

Fig. 1 Schematic of the process used in this study for the synthesis of self-healing material.

(98\%) were obtained from Chengdu Kelong Chemical Reagent Factory. All the above-mentioned materials were analytically pure.

\subsection{Instruments and characterization}

${ }^{1} \mathrm{H}$ and ${ }^{13} \mathrm{C}$ NMR spectra were recorded using a Bruker AVANCE AV II-600 NMR spectrometer. Mass spectrometry measurements were conducted on LCQ Deca LC-MS. One-dimensional Fourier infrared (FT-IR) spectra were recorded with a Nicolet 560 Fourier transform infrared spectrometer, and two-dimensional Fourier infrared (2DIR) characterization was conducted by a Nicolet 710 FT-IR spectrometer (coupled with a control temperature instrument) and a DTGS detector. The storage modulus and glass transition temperature of samples were determined using a Q800 Dynamic mechanical thermal analyzer. Tensile tests were performed on an AG-10TA tensile testing machine. Thermogravimetry analysis of $\mathrm{Al}_{2} \mathrm{O}_{3} \mathrm{NPs}, \mathrm{NH}_{2}-\mathrm{Al}_{2} \mathrm{O}_{3}$ NPs, and $\mathrm{CD}-\mathrm{Al}_{2} \mathrm{O}_{3}$ NPs was carried out using a Q-500 thermal analyzer of TA. The self-healing property of the damage was observed under VHX-1000C Digital Microscopes, and the tensile stresses of the sample before and after self-healing were tested by an AG-10TA tensile testing machine.

\subsection{Fabrication method}

(a) Synthesis of guest and host molecules. The details of the synthesis of guest molecule HEMA-Ad and host molecule CD$\mathrm{Al}_{2} \mathrm{O}_{3}$ NPs are presented in ESI $2 . \dagger$

(b) Synthesis of self-healing material PVP/p(HEMA-co-BA). First, $\mathrm{CD}-\mathrm{Al}_{2} \mathrm{O}_{3}$ NPs were ultrasonically dispersed in $3 \mathrm{~mL}$ of DMF for $30 \mathrm{~min}$ and then, HEMA-Ad was added. After stirring for $24 \mathrm{~h}$, PVP, HEMA, BA, EGDMA, and AIBN were added in certain proportions. After reaction at $75{ }^{\circ} \mathrm{C}$ for some time with stirring, the solution was allowed to react for 10 hours without stirring. Finally, the solvent was removed in a vacuum drying oven to obtain PVP/

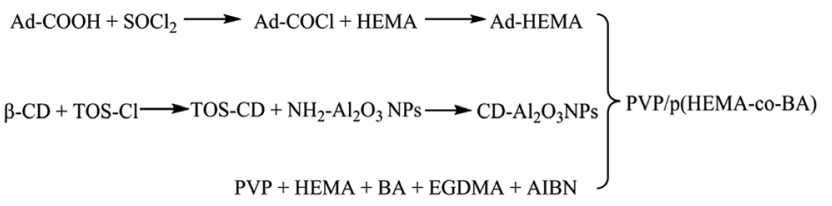

Fig. 2 Chemical reaction diagram of the self-healing material. 
Table 1 Composition of samples

\begin{tabular}{lllllll}
\hline Sample & HEMA $/ \mathrm{mL}$ & $\mathrm{BA} / \mathrm{mL}$ & $\mathrm{PVP} / \mathrm{g}$ & $\mathrm{HEMA}-\mathrm{Ad} / \mathrm{g}$ & $\mathrm{CD}_{-\mathrm{Al}} \mathrm{O}_{3} \mathrm{NPs} / \mathrm{g}$ & $\mathrm{EGDMA} / \mu \mathrm{L}$ \\
\hline 1 & 0.5 & 2.37 & 0.66 & 0.6 & 0.3 & 0.3 \\
2 & 0.5 & 2.37 & 0.66 & 0.6 & 0.3 & 0.3 \\
3 & 0.5 & 2.37 & 0.66 & 0.6 & 0.3 & 1 \\
4 & 0.5 & 2.37 & 0.66 & 0.6 & 0.2 & 1 \\
5 & 0.5 & 2.37 & 0.66 & 0.6 & 0.1 & 1 \\
6 & 0.5 & 2.37 & 0.66 & 0.6 & 0 & 1 \\
Ref. sample 1 & 0.5 & 2.37 & 0.66 & 0.6 & 0.3 & 1 \\
Ref. sample 2 & 0.5 & 2.37 & 0 & 0.6 & &
\end{tabular}

$\mathrm{p}$ (HEMA-co-BA) self-healing material. The reaction diagram is shown in Fig. 2, and the amounts of reagents added are shown in Table 1.

\section{Results and discussion}

\subsection{Grafting effects of host molecule and guest molecule}

The grafting effects of host molecule $\mathrm{CD}-\mathrm{Al}_{2} \mathrm{O}_{3}$ NPs and guest molecule HEMA-Ad were analyzed by ${ }^{1} \mathrm{H}$ NMR and ${ }^{13} \mathrm{C}$ NMR spectra, and the results are shown in S1a and b and S2a and $\mathrm{b} . \dagger$

\subsection{Host molecule $\mathrm{CD}-\mathrm{Al}_{2} \mathrm{O}_{3} \mathrm{NPs}$}

The FT-IR spectra of $\mathrm{Al}_{2} \mathrm{O}_{3}$ NPs, CD- $\mathrm{Al}_{2} \mathrm{O}_{3}$ NPs, and TOS-CDs were examined; the results are shown in Fig. 3. Compared to the peaks in the FT-IR spectra of $\mathrm{Al}_{2} \mathrm{O}_{3}$ NPs, the three new characteristic peaks of $\mathrm{CD}-\mathrm{Al}_{2} \mathrm{O}_{3}$ NPs at 1038,1149 , and $1490 \mathrm{~cm}^{-1}$ corresponded to $v_{\mathrm{C}-\mathrm{O}-\mathrm{C}}$ and $\delta_{\mathrm{C}-\mathrm{O}-\mathrm{C}}$ on cyclodextrin and $\delta_{\mathrm{NH}}$ on the amide groups. In addition, compared to the peaks in the FTIR spectra of TOS-CD, $v_{\mathrm{C}=\mathrm{C}}\left(\right.$ at $1369 \mathrm{~cm}^{-1}$ and $\left.1419 \mathrm{~cm}^{-1}\right)$ on the benzene ring was not observed in the infrared spectrum of CD- $\mathrm{Al}_{2} \mathrm{O}_{3}$ NPs, confirming that $\mathrm{Al}_{2} \mathrm{O}_{3}$ NPs were successfully modified by cyclodextrin.

On the other hand, thermogravimetric analyses (TGA) of $\mathrm{Al}_{2} \mathrm{O}_{3}$ NPs, $\mathrm{NH}_{2}-\mathrm{Al}_{2} \mathrm{O}_{3}$ NPs, and $\mathrm{CD}-\mathrm{Al}_{2} \mathrm{O}_{3}$ NPs are shown in Fig. 4. From Fig. 4, it can be seen that the loss mass of $\mathrm{Al}_{2} \mathrm{O}_{3}$ NPs in the region between $50{ }^{\circ} \mathrm{C}$ and $800{ }^{\circ} \mathrm{C}$ is $0.21 \%$ and that of $\mathrm{NH}_{2}-\mathrm{Al}_{2} \mathrm{O}_{3}$ NPs is $5.71 \%$, thus indicating that organics are modified on the nanoparticles. The difference between the loss mass of CD- $\mathrm{Al}_{2} \mathrm{O}_{3}$ NPs $(24.35 \%)$ and that of $\mathrm{NH}_{2}-\mathrm{Al}_{2} \mathrm{O}_{3}$ NPs is $18.64 \%$, which proves that cyclodextrin is successfully modified on $\mathrm{Al}_{2} \mathrm{O}_{3}$ NPs.

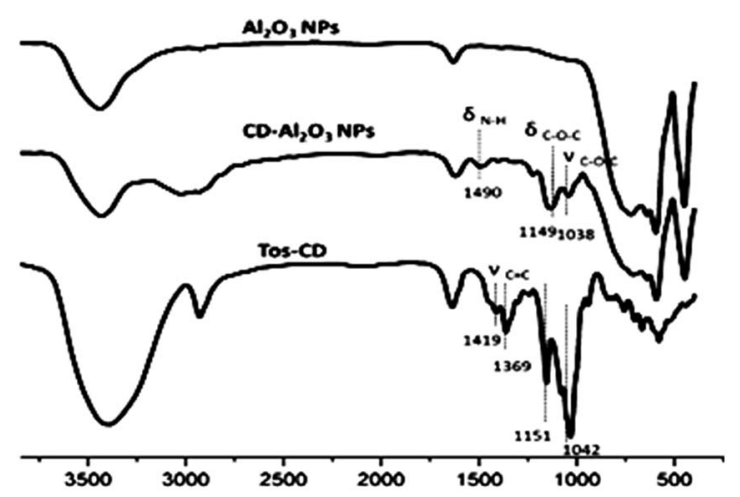

Fig. 3 Infrared spectra of $\mathrm{Al}_{2} \mathrm{O}_{3} \mathrm{NPs}, \mathrm{CD}-\mathrm{Al}_{2} \mathrm{O}_{3} \mathrm{NPs}$ and TOS-CD.

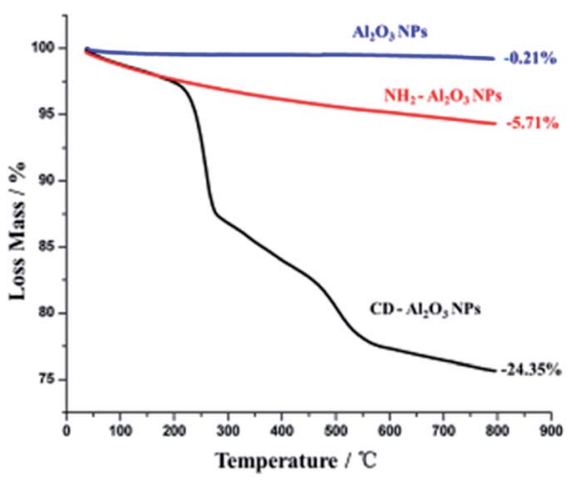

Fig. 4 Thermogravimetric analyses of $\mathrm{Al}_{2} \mathrm{O}_{3} \mathrm{NPs}, \mathrm{NH}_{2}-\mathrm{Al}_{2} \mathrm{O}_{3} \mathrm{NPs}$, and $\mathrm{CD}-\mathrm{Al}_{2} \mathrm{O}_{3} \mathrm{NPS}$.

According to previous reports, ${ }^{27}$ an estimated total of 3710 cyclodextrins can be modified on each nanoparticle.

\subsection{PVP/p(HEMA-co-BA) self-healing material}

To establish that the crosslinked network in PVP/p(HEMA-coBA) material is formed by PVP and p(HEMA-co-BA) through hydrogen bonding between the carbonyl groups on polyvinylpyrrolidone and the hydroxyl groups, we used infrared spectroscopy to characterize the hydrogen bonds of PVP and $\mathrm{PVP} / \mathrm{p}($ HEMA-co-BA) material (sample 3 and 1 in Table 1). The results are shown in Fig. 5.

Table 2 dynamic thermo-mechanical analysis of PVP/ p(HEMA-co-BA)The peaks of PVP at 2923, 1655, 1458, and $1285 \mathrm{~cm}^{-1}$ correspond to the stretching vibration of $\mathrm{O}-\mathrm{H}$, the stretching vibration of $\mathrm{C}=\mathrm{O}$, the bending vibration of $\mathrm{CH}_{2}$, and the vibration of $\mathrm{C}-\mathrm{N}$. In the spectrum of $\mathrm{PVP} / \mathrm{p}(\mathrm{HEMA}-\mathrm{co}-\mathrm{BA})$

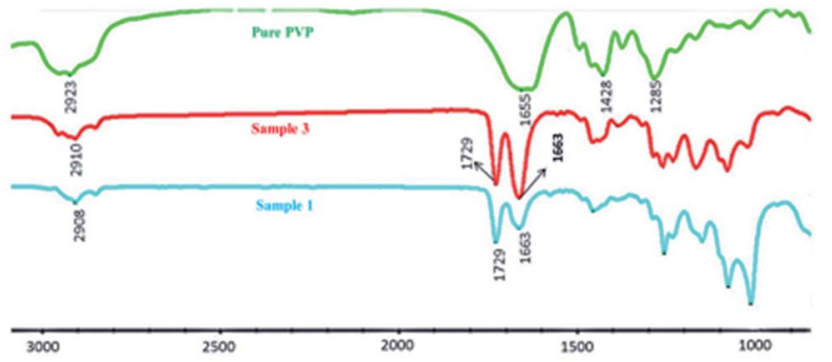

Fig. 5 Infrared spectrum of PVP and PVP/p(HEMA-co-BA) material. 
Table 2 Dynamic thermo-mechanical analysis of PVP/p(HEMA-coBA) materials

\begin{tabular}{|c|c|c|c|c|c|c|}
\hline \multirow[b]{2}{*}{ Sample } & \multicolumn{3}{|c|}{$\begin{array}{l}\text { Storage modulus/ } \\
\mathrm{MPa}\end{array}$} & \multirow{2}{*}{$\frac{r_{E^{\prime} 1}}{\left(E^{\prime}{ }_{20^{\circ} \mathrm{C}} / E^{\prime}{ }_{50^{\circ} \mathrm{C}}\right)}$} & \multirow{2}{*}{$\frac{r_{E^{\prime} 1}}{\left(E^{\prime}{ }_{50^{\circ} \mathrm{C}} / E^{\prime}{ }_{90^{\circ} \mathrm{C}}\right)}$} & \multirow[b]{2}{*}{$T_{\mathrm{g}} /{ }^{\circ} \mathrm{C}$} \\
\hline & $20^{\circ} \mathrm{C}$ & $50^{\circ} \mathrm{C}$ & $90^{\circ} \mathrm{C}$ & & & \\
\hline 2 & 300.8 & 48.8 & 1.1 & 6.16 & 43.32 & 78.1 \\
\hline 3 & 399.0 & 79.1 & 2.3 & 5.04 & 34.21 & 81.3 \\
\hline 4 & 432.3 & 64.8 & 1.0 & 6.67 & 62.08 & 95.8 \\
\hline
\end{tabular}

material, it can be seen that the stretching vibration peak of $\mathrm{C}=\mathrm{O}$ shifts from $1655 \mathrm{~cm}^{-1}$ to $1663 \mathrm{~cm}^{-1}$, indicating that the carbonyl and hydroxyl groups in the material form hydrogen bonds.

To verify the host-guest interaction between cyclodextrin and adamantane in the PVP/p(HEMA-co-BA) material, it (sample 3 in Table 1) was tested by two-dimensional infrared spectroscopy, which is an effective tool to study molecular interactions in many systems. ${ }^{28}$ The results are shown in Fig. 6a and b (a and $\mathrm{b}$ are the synchronous and asynchronous 2D infrared signals of the material, respectively). According to the theory of $2 \mathrm{D}$ IR spectroscopy developed by Noda, ${ }^{29}$ a correlation peak is formed when two dipole transition moments associated with the molecular vibrations of different functional groups are reorienting simultaneously. The cooperative motion of local structures is expected when strong interactions exist among different functional groups. In Fig. 6a, the peaks at $1161 \mathrm{~cm}^{-1}$ and $1082 \mathrm{~cm}^{-1}$ correspond to the $\mathrm{C}-\mathrm{O}-\mathrm{C}$ bending vibration and the $\mathrm{C}-\mathrm{C}-\mathrm{C}-\mathrm{O}$ bending vibration of cyclodextrin. Moreover, the peak at $1103 \mathrm{~cm}^{-1}$ is due to the bending vibration of $\mathrm{CH}_{2}$ on adamantane. It is clear that the characteristic peaks of $\beta$-CD (at $1161 \mathrm{~cm}^{-1}$ and $1082 \mathrm{~cm}^{-1}$ ) and Ad (at $1103 \mathrm{~cm}^{-1}$ ) show clear correlations (shown in the red box in Fig. 6a). The results indicate that $\beta-\mathrm{CD}$ and $\mathrm{Ad}$ in the material interact with each other strongly due to the host-guest interactions.

\subsection{Thermal properties of PVP/p(HEMA-co-BA)}

To study the glass transition temperature $\left(T_{\mathrm{g}}\right)$ of PVP/p(HEMA$c o$-BA) material, dynamic thermo-mechanical analysis (DMA) was performed, and the results were used to obtain the $\tan \delta$ curve, as shown in Fig. 7 and Table 2.

The glass transition temperature of sample 4 is the highest $\left(T_{g}=95^{\circ} \mathrm{C}\right)$, whereas the $T_{\mathrm{g}}$ values of sample 3 and sample 2 are
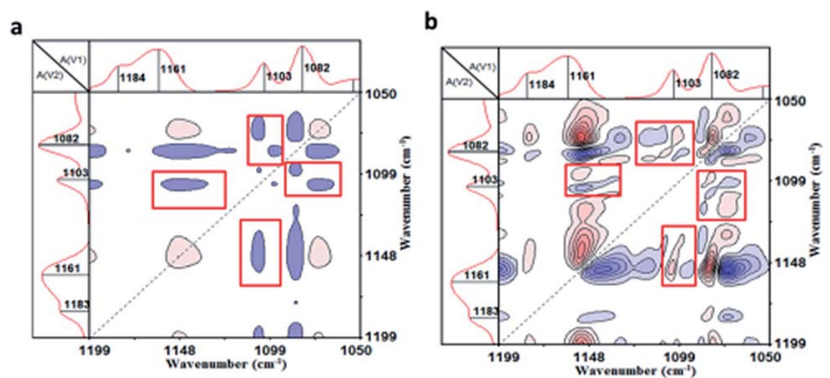

Fig. 6 Two-dimensional infrared spectra of the material: (a) synchronous infrared signal, (b) asynchronous infrared signal.

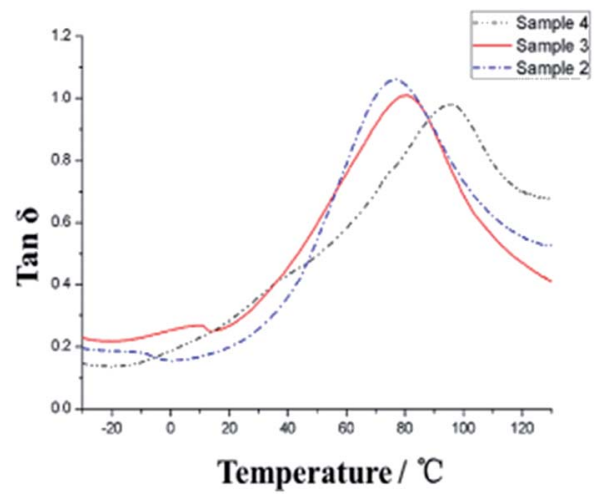

Fig. 7 Glass transition temperature curve of PVP/p(HEMA-CO-BA) material (samples 2, 3, and 4).

$81^{\circ} \mathrm{C}$ and $78^{\circ} \mathrm{C}$, respectively, indicating that the glass transition temperature of the sample increases with the increasing amount of the crosslinking agent as the chemical crosslinking points limit the segmental motion of the material. At the same time, it can be observed that all the three samples have a very wide glass transition temperature, e.g., sample 3 with $T_{\mathrm{g}}$ of 20$140{ }^{\circ} \mathrm{C}$. This is because of the presence of two kinds of supramolecular forces in the material, namely, host-guest interaction of adamantane and cyclodextrin and hydrogen bonding of hydroxyl and carbonyl groups, which make the material microphase separated, and the different segmental motions of the micro-phases give rise to different $T_{\mathrm{g}}$ temperatures, ultimately resulting in very wide $T_{\mathrm{g}}$ peak overall. In addition, at $20^{\circ} \mathrm{C}$, the storage moduli of the three samples increase $(308,399$ and $432 \mathrm{MPa}$, respectively) with the increasing amount of crosslinking agents. The resistance temperature of the material was obtained through thermogravimetric analysis (TGA), as shown in Fig. 8.

There is no clear mass loss of the material till $257^{\circ} \mathrm{C}$, indicating that the PVP/p(HEMA-co-BA) material can withstand temperatures up to $257^{\circ} \mathrm{C}$. At the same time, it can also be seen that the mass percentage of $\mathrm{Al}_{2} \mathrm{O}_{3} \mathrm{NPs}$ in the material is $16.7 \%$, which is consistent with the ratio present in sample 3 .

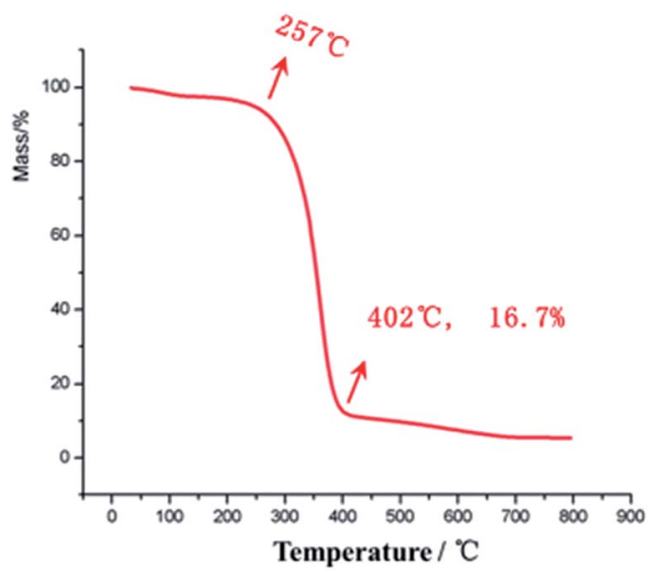

Fig. 8 Thermogravimetric curves of sample 3. 
Table 3 Insulation properties of PVP/p(HEMA-co-BA)

\begin{tabular}{lllll}
\hline No. & Properties & & Unit & Results \\
\hline 1 & Volume resistivity & Normal & $\Omega \mathrm{m}$ & $3.2 \times 10^{7}$ \\
& & $50^{\circ} \mathrm{C}$, vacuum 2 h & & $4.1 \times 10^{8}$ \\
2 & Surface resistivity & Normal & $\Omega$ & $7.2 \times 10^{10}$ \\
& & $50^{\circ} \mathrm{C}$, vacuum 2 h & & $3.5 \times 10^{10}$ \\
3 & Relative permittivity & Normal & - & 21.7 \\
& & $50^{\circ} \mathrm{C}$, vacuum 2 h & & 18.7 \\
4 & AC electrical strength & & $\mathrm{MV} \mathrm{m}^{-1}$ & 12.5 \\
& (in oil) & & \\
DC electrical strength & & $\mathrm{MV} \mathrm{m}^{-1}$ & 14.7 \\
& (in oil) & &
\end{tabular}

\subsection{Insulation properties of PVP/p(HEMA-co-BA)}

The insulation properties of PVP/p(HEMA-co-BA) were tested. The results are shown in Table 3 . It can be seen from Table 3 that the volume resistivity of the material reached $10^{7}-10^{8}$, and the surface resistivity reached $10^{10}$, which can meet the insulation requirements for general engineering use (usually greater than $10^{6}$ ). The relative permittivity of the material under normal state was 21.7 , which was higher than that of polyvinyl chloride (4.8). The material also exhibited good AC and DC electrical strength values (its values were as high as $12.5 \mathrm{MV} \mathrm{m}^{-1}$ and 14.7 $\mathrm{MV} \mathrm{m}^{-1}$, respectively), which were greater than the limit of general cable sheath insulation materials (the requirement is greater than $1 \mathrm{MV} \mathrm{m}^{-1}$ ).

\subsection{Self-healing property of PVP/p(HEMA-co-BA)}

To investigate the self-healing property of PVP/p(HEMA-co-BA) material, the sample was cut into two pieces with a blade, and the broken ends were brought together immediately. After 2 hours at room temperature, the pieces were found to have rejoined by self-healing (shown in Fig. 9a). Moreover, the sample was cut off at the original fracture to investigate if it could self-heal again; the results showed that the material had achieved the ability to self-heal multiple times.

To observe the healing more clearly, a 3D digital microscope was used for detection. The result is shown in Fig. 9b. The

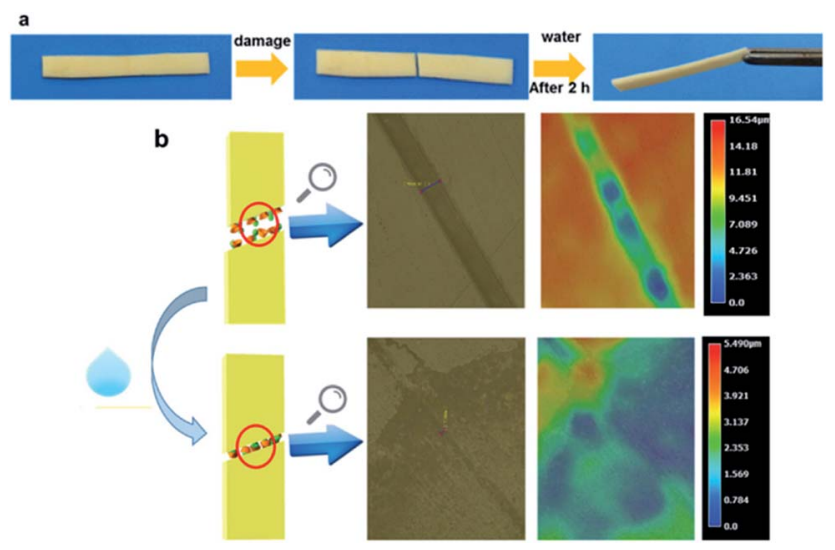

Fig. 9 Self-healing of PVP/p(HEMA-CO-BA) material: (a) self-healing process of the material; (b) 3D ultra-depth of focus images of the material before and after self-healing.
Table 4 Mechanical properties and self-healing efficiency of PVP/ $\mathrm{p}$ (HEMA-CO-BA)

\begin{tabular}{|c|c|c|c|c|c|c|}
\hline \multirow[b]{2}{*}{ Sample } & \multirow[b]{2}{*}{$E_{\mathrm{r}} / \mathrm{MPa}$} & \multicolumn{2}{|l|}{$\varepsilon / \%$} & \multicolumn{2}{|l|}{$\sigma / \mathrm{MPa}$} & \multirow{2}{*}{$\begin{array}{l}\text { Self-healing } \\
\text { efficiency }(\eta)\end{array}$} \\
\hline & & Before & After & Before & After & \\
\hline 1 & 0.36 & 337 & 225 & 0.61 & 0.52 & $85 \%$ \\
\hline 2 & 7.64 & 173 & 24 & 0.81 & 0.59 & $73 \%$ \\
\hline 3 & 9.42 & 161 & 70 & 1.45 & 0.99 & $68 \%$ \\
\hline 4 & 15.0 & 98 & 29 & 2.04 & 1.34 & $66 \%$ \\
\hline 5 & 9.30 & 165 & 43 & 1.48 & 0.77 & $52 \%$ \\
\hline 6 & 9.22 & 159 & 24 & 1.40 & 0.46 & $33 \%$ \\
\hline Ref. 1 & 9.14 & 158 & 0 & 1.43 & 0 & 0 \\
\hline
\end{tabular}

material in Fig. 9b has a damage $28.5 \mu \mathrm{m}$ in width and $16.54 \mu \mathrm{m}$ in depth. After self-healing, only a trace of the damage is retained on the surface, indicating that the PVP/p(HEMA-co-BA) material indeed exhibits self-healing properties.

To investigate the self-healing efficiency of the PVP/p(HEMAco-BA) material and the effect of the cross-linker dosage on selfhealing properties, a tensile testing machine was used to study the mechanical properties of the samples before and after selfhealing at the drawing speed of $5 \mathrm{~mm} \min ^{-1}$. The results (including Young modulus $E_{\mathrm{Y}}$, breaking elongation $\varepsilon$, breaking strength $\sigma$, and self-healing efficiency $\eta$ ) of the samples before and after self-healing are listed in Table 4; as the cross-linker dosage in the material increased (the irreversible cross-linking point increased), the Young modulus $E_{\mathrm{Y}}$ and the breaking strength $\sigma$ increased significantly, whereas the breaking elongation $\varepsilon$ decreased rapidly; this indicated that within a certain range, the less the cross-linker, the higher the self-healing efficiency (up to $85 \%$ ).

To prove that the self-healing property of PVP/p(HEMA-coBA) material is derived from the inclusion effect of the host ( $\beta$ CD group) and the guest groups (Ad group), three groups of control experiments were designed: (1) samples without CD$\mathrm{Al}_{2} \mathrm{O}_{3}$ NPs were prepared. The results showed that the material had no self-healing property (Fig. 10a); (2) samples without PVP were prepared. The results showed that the material had selfhealing property (Fig. 10b); (3) the PVP/p(HEMA-co-BA) material was cut, and cyclodextrin solution was smeared on the cut
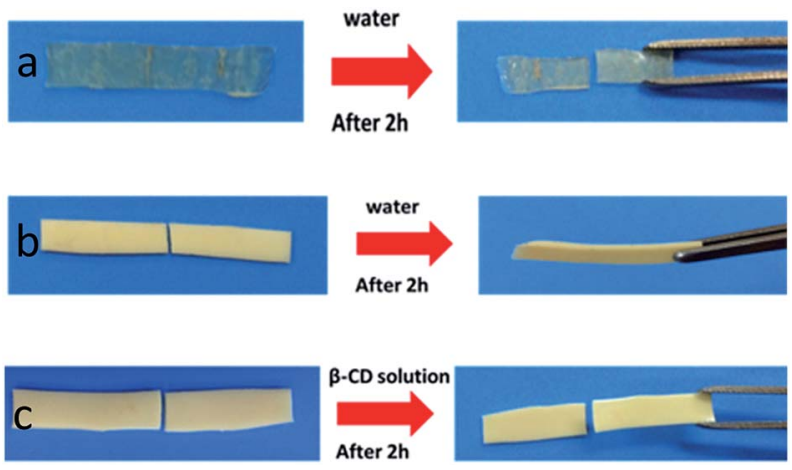

Fig. 10 Self-healing tests using different materials: (a) samples without $\mathrm{CD}-\mathrm{Al}_{2} \mathrm{O}_{3} \mathrm{NPs}$; (b) samples without PVP; (c) self-healing test of PVP/ $\mathrm{p}(\mathrm{HEMA}-\mathrm{CO}-\mathrm{BA})$ after smearing cyclodextrin solution at cutting surface. 
surface; then, the self-healing properties were measured. The results showed that the material could not self-heal (Fig. 10c).

The two sets of experiments shown in Fig. 10a and b demonstrate that the self-healing property does not rely on the interaction between the carbonyl group on PVP and the hydroxyl group on $\mathrm{p}$ (HEMA-co-BA) but rather on the host-guest interaction between cyclodextrin and adamantane. The sample shown in Fig. 10c cannot self-heal because the cyclodextrin molecule in the cyclodextrin solution rather than cyclodextrin molecule in material complex with adamantane molecule on the cutting surface, which means that the cyclodextrin molecule in the solution acts as a competitive molecule. Consequently, the host and guest molecules at the cutting surface cannot form inclusion complexes, thus preventing self-healing of materials.

\section{Conclusion}

Based on the inclusion effect of the host and guest molecules, this paper presented a novel self-healing material synthesized by free radical copolymerization. The ${ }^{1} \mathrm{H}$ and ${ }^{13} \mathrm{C}$ NMR spectra verified that HEMA was successfully grafted on $\mathrm{Ad}$, and $\mathrm{Al}_{2} \mathrm{O}_{3}$ NPs were successfully grafted on CD. One-dimensional and twodimensional infrared spectra showed the existence of two kinds of supramolecular interactions in the material: the host-guest interaction and the hydrogen bonding interaction. The PVP/ $\mathrm{p}$ (HEMA-co-BA) self-healing material showed good thermal stability with the heat resisting temperature of $200{ }^{\circ} \mathrm{C}$. The thermogravimetric analysis revealed that the storage modulus of the sample at $20{ }^{\circ} \mathrm{C}$ increased with the increase in crosslinker dosage, the highest being $432 \mathrm{MPa}$. The results from 3D ultra-depth of focus imaging and tensile tests showed that the material possessed self-healing property and it can self-heal multiple times; the self-healing efficiency increased with a decrease in cross-linker dosage. Moreover, the tensile test showed that the mechanical strength (Young modulus $E_{\mathrm{Y}}$ ) of the material was up to $15 \mathrm{MPa}$, and the mechanical strength was satisfactory.

\section{Conflicts of interest}

There are no conflicts to declare.

\section{Acknowledgements}

This research is supported by China Postdoctoral Science Foundation Grant (2018M630920) and China Southern Power Grid project (number GDKJQQ20152049).

\section{References}

1 T. Seguchi, K. Tamura, T. Ohshima, A. Shimada and H. Kudoh, Radiat. Phys. Chem., 2011, 80, 268.

2 A. Tzimas, S. Rowland, L. A. Dissado, M. Fu and U. H. Nilsson, IEEE Trans. Dielectr. Electr. Insul., 2009, 16, 1436.
3 Z. Jiao and Q. Xia, Distribution \& Utilization, 2011, 28, 64, (in Chinese).

4 D. E. Vokey and M. Loewen, US Pat. No. 6,181,140, 2001.

5 J. L. Mynar and T. Aida, Nature, 2008, 451, 895.

6 S. M. Bleay, C. B. Loader, V. J. Hawyes, L. Humberstone and P. T. Curtis, Composites, Part A, 2001, 32, 1767.

7 R. S. Trask, G. J. Williams and I. P. Bond, J. R. Soc., Interface, 2007, 4, 363.

8 S. R. White, N. R. Sottos, P. H. Geubelle, J. S. Moore, M. R. Kessler, S. R. Sriram, E. N. Brown and S. Viswanathan, Nature, 2001, 409, 794.

9 M. Keller, S. White and N. Sottos, Adv. Funct. Mater., 2010, 17, 2399.

10 J. D. Rule, E. N. Brown, N. R. Sottos, S. R. White and J. S. Moore, Adv. Mater., 2005, 17, 205.

11 K. S. Toohey, N. R. Sottos, J. A. Lewis, J. S. Moore and S. R. White, Nat. Mater., 2007, 6, 581.

12 K. S. Toohey, C. J. Hansen, J. A. Lewis, S. R. White and N. R. Sottos, Adv. Funct. Mater., 2009, 19, 1399.

13 X. Chen, F. Wudl, A. K. Mal, H. Shen and S. R. Nutt, Macromolecules, 2003, 36, 1802.

14 J. Ling, M. Z. Rong and M. Q. Zhang, J. Mater. Chem., 2011, 21, 18373.

15 M. Krogsgaard, M. A. Behrens, J. S. Pedersen and H. Birkedal, Biomacromolecules, 2013, 14, 297.

16 P. Cordier, F. Tournilhac, C. Soulié-Ziakovic and L. Leibler, Nature, 2008, 451, 977.

17 S. Burattini, H. M. Colquhoun, J. D. Fox, D. Friedmann, B. W. Greenland, P. J. F. Harris, W. Hayes, M. E. Mackay and S. J. Rowan, Chem. Commun., 2009, 44, 6717.

18 S. Burattini, B. W. Greenland, D. H. Merino, W. Weng, J. Seppala, H. M. Colquhoun, W. Hayes, M. E. Mackay, I. W. Hamley and S. J. Rowan, J. Am. Chem. Soc., 2010, 132, 12051.

19 S. Bode, L. Zedler, F. H. Schacher, B. Dietzek, M. Schmitt, J. Popp, M. D. Hager and U. S. Schubert, Adv. Mater., 2013, $25,1634$.

20 M. Nakahata, Y. Takashima, H. Yamaguchi and A. Harada, Nat. Commun., 2011, 2, 511.

21 M. Zhang, D. Xu, X. Yan, J. Chen, S. Dong, B. Zheng and F. Huang, Angew. Chem., 2012, 51, 7011.

22 Q. Wang, J. L. Mynar, M. Yoshida, E. Lee, M. Lee, K. Okuro, K. Kinbara and T. Aida, Nature, 2010, 463, 339.

23 D. L. Zhang, X. Ju, L. H. Li, Y. Kang, X. L. Gong, B. J. Li and S. Zhang, Chem. Commun., 2015, 51, 6377.

24 R. Hoogenboom, Angew. Chem., Int. Ed., 2012, 51, 11942.

25 J. L. Wietor and R. P. Sijbesma, Angew. Chem., 2008, 47, 8161.

26 J. P. Morel and N. Morel-Desrosiers, J. Solution Chem., 1981, $10,451$.

27 Y. Wu, F. Zuo, Z. Zheng, X. Ding and Y. Peng, Nanoscale Res. Lett., 2009, 4, 738.

28 D. E. Rosenfeld, Z. Gengeliczki, B. J. Smith, T. D. P. Stack and M. D. Fayer, Science, 2011, 334, 634.

29 I. Noda, J. Am. Chem. Soc., 1989, 111, 8116. 